\title{
Alunos do Ensino Fundamental e professores construindo espaços de Educação a Distância na Escola
}

\author{
Luciane Magalhães Corte Real' ${ }^{1}$, Mara Rosane Noble Tavares ${ }^{2}$ \\ ${ }^{1}$ Faculdade de Educação - Universidade Federal do Rio Grande do Sul (UFRGS) \\ ${ }^{2}$ Secretaria da Educação do Estado do Rio Grande do Sul (SEC-RS) \\ lucreal@gmail.com, maratavares@professor.rs.gov.br
}

\begin{abstract}
Resumo: O presente artigo é um relato de experiência da construção de um site educacional na plataforma Pbworks realizada em uma escola pública estadual do Rio Grande do Sul. O objetivo do site é manter um espaço colaborativo para a construção de conhecimentos de professores e alunos, abrigando atividades desenvolvidas na Sala do espaço por alunos $e$ professores, ressaltando a importância do professor mediador do Laboratório de Informática ser ativo tanto em relação a tecnologia quanto nas intervenções pedagógicas.
\end{abstract}

Palavras-chave: Ensino Fundamental, Informática na Educação, Educação à Distância.

\begin{abstract}
This paper is an experience report of a construction site in the educational platform PBworks held in a public school in Rio Grande do Sul The site's purpose is to maintain a space for collaborative knowledge building housing for teachers and students activities in Room Computing Environment (SAI). It is a qualitative research in the form of a case study whose results positively indicate the use of space for students and teachers emphasizing the importance of the teacher's Computer Laboratory mediator be active both in relation to technology and educational interventions.
\end{abstract}

Keywords: Elementary Education, Computers in Education, Distance Education.

\section{Apresentação}

O uso das tecnologias estão presentes no dia a dia de professores e estudantes. Vários investigadores trabalham sobre o tema da utilização das Tecnologias da Informação e da Comunicação (TICs) no Ensino Fundamental abordando a utilização de wikis, propostas dentro dos Laboratórios de Informáticas das Escolas, o uso da Internet, entre outros (Real, 2007; Mattos et al, 2005; Haetinger et al, 2006; Real, Axt e Maraschin, 2007; Bittencourt et al, 2011; Real e Picetti, 2011).

O presente artigo descreve uma experiência pedagógica na criação e manutenção de um site educacional na plataforma Pbworks, realizada em uma escola pública estadual no Rio Grande do Sul. O objetivo da experiência foi construir e manter um espaço 
colaborativo para a construção de conhecimentos abrigando as atividades desenvolvidas na Sala Ambiente de Informática (SAI) para que alunos e professores possam utilizar os diversos espaços onde a Internet está presente, na casa dos alunos, em lan houses, casa de amigos, etc.

\section{Ambientes Colaborativos de Aprendizagem}

Com a mudança no paradigma educacional à distância e seu crescimento, houve a necessidade de demandar ferramentas simples que permitam o trabalho colaborativo entre alunos, tutores e professores na Internet. Nesse contexto, o Pbworks se destaca como uma ferramenta de fácil manejo, exigindo poucos conhecimentos técnicos dos usuários, e permitindo a interação dinâmica entre seus membros, através da criação de páginas na web em questão de poucos minutos. Segundo Zeide et al (2009), é uma ferramenta eletrônica de fácil uso na construção de páginas na web, permitindo que vários usuários interajam, publiquem, editem, alterem seu conteúdo e armazenem arquivos, através de um sistema de trabalho simultâneo e colaborativo. Os "workspaces" (espaços de trabalho) criados podem ser públicos ou privados, gratuitos ou pagos, podendo remeter a outros sites; seu funcionamento é em grande parte semelhante ao de hospedagem de blogs. Destinam-se a construção e edição de páginas da web, além da elaboração, edição e armazenamento de arquivos; tudo pode ser feito de forma colaborativa.

Real e Corbellini et al (2011) utilizam o PBworks na construção de trabalhos de conclusão de curso (TCC) e referem que o PBworks ajudou na colaboração e cooperação entre alunos, professores e tutores, pois cada autor podia interagir de um espaço diferente, assíncrono, e contribuir no trabalho do colega. Schäfer, Lacerda e Fagundes (2009) afirmam que as habilidades colaborativas já são uma realidade para o aluno da cultura digital, pois ele estabelece redes, cria comunidades e nelas compartilha ideias. A criação de páginas passíveis de edição coletiva e constante atualização, viabilizada pela linguagem wiki, possibilita a emergência de construções coletivas do conhecimento.

Os autores Gomes et al (2009) diferenciam a wiki de outros editores de texto principalmente no que tange à historicidade da produção, a qual oportuniza o acompanhamento dos processos de produção e colaboração entre os usuários, tanto pelo fato do acesso remoto ao registro quanto pela recuperação da história do documento produzido.

Para Piaget (1998), os ambientes colaborativos de aprendizagem são espaços desenvolvidos para estimular a interação entre os sujeitos na construção de aprendizagens. Embora o conceito seja anterior à popularização da Internet, foi por meio de sua facilidade em permitir a formação de redes sociais que o conceito passou a descrever não só os ambientes de aprendizagem colaborativa apoiada por computador, mas também as novas posturas adotadas por professores e alunos na utilização das tecnologias durante o processo. $\mathrm{O}$ que torna o Pbworks um instrumento adequado como ambiente virtual para o desenvolvimento de aprendizagens colaborativas.

\section{O uso da Sala Ambiente de Informática (SAI) da Escola}


O trabalho com Informática Educativa, na escola em que se realizou a experiência de construção do site, está previsto no Regimento Escolar. É desenvolvido pelo professor titular da turma ou responsável por uma área do conhecimento e em conjunto com o professor responsável pela Sala Ambiente de Informática (SAI). Além dos conteúdos, também são desenvolvidos Projetos de Aprendizagem, de Estudo ou de Trabalho, de maneira autônoma ou em parceria com as disciplinas, mantendo o enfoque interdisciplinar. A Equipe Diretiva da Escola apóia os espaços de construção de conhecimentos para o uso das Novas Tecnologias.

As atividades realizadas na SAI têm a intencionalidade de construir habilidades e competências sociais e cognitivas, nas áreas da linguagem, da pesquisa, do desenvolvimento da acuidade visual e auditiva, da interpretação, da compreensão e da colaboração para resolver diferentes problemas que, além de específicos, colaboram para a construção da cidadania.

\section{O uso do Pbworks desafiando a aprendizagem}

Segundo Papert (1994), ao longo da história, muitos educadores buscaram aproximar os métodos de ensino da maneira como a criança aprende. Papert (1994) destaca que Freire defendia a ideia de que, se as crianças se encarregassem de seus próprios processos de aprendizagem, aprenderiam melhor.

No cotidiano da escola, observa-se que com a evolução da tecnologia e seu uso nos lares, fábricas, escritórios, comércio, bancos, etc., muitos educadores utilizam computadores, Internet e celulares com câmera na tentativa de unir novas e antigas estratégias, para melhor explorar os usos da tecnologia no processo de ensino/aprendizagem.

A estratégia de utilização do Pbworks na escola é a partir do conceito de Arquitetura Pedagógica (AP) no sentido de inovação. Carvalho, Nevado e Menezes (2005), propõem este conceito para unir os instrumentos tecnológicos a diferentes estratégias numa prática pedagógica mais flexível. Conforme esses pesquisadores, as Arquiteturas Pedagógicas são “[...] uma combinação de estratégias, dinâmicas de grupo, softwares educacionais e ferramentas de apoio à cooperação, voltadas para o favorecimento da aprendizagem". A Arquitetura Pedagógica compreende a produção de um objeto que represente a síntese do trabalho de pesquisa, levantamento de hipóteses, trabalho colaborativo e autoria nas aprendizagens realizadas ao longo do processo (Carvalho, Nevado e Menezes, 2005). Como ferramenta de apoio à cooperação na Arquitetura Pedagógica, o Pbworks permite o acompanhamento do processo de criação e edição do conteúdo até chegar à síntese, a construção que caracteriza o objeto de aprendizagem.

Tanto nas ações, com uso de tecnologia, no caso computadores, filmadoras, máquinas digitais, celulares, etc., como nas ações sem o uso de tecnologia, a Arquitetura Pedagógica compreende a produção de um objeto que represente a síntese do trabalho de pesquisa, levantamento de hipóteses, trabalho colaborativo e autoria nas aprendizagens realizadas ao longo do processo. A apresentação dos resultados poderá ser feita com outros recursos, que não os midiáticos, para exposição desses objetos. 
Fagundes et al (2000) refere que navegar na internet é uma prática social característica do nosso tempo. Neste sentido, o uso do PBworks representa um desafio para professores e alunos em transformar esta ferramenta em uma rede de colaboração e cooperação.

Algumas experiências utilizando o PBworks foram a partir da proposta metodológica de Projetos de Aprendizagem como descrito por Fagundes et al (2000), um projeto que levanta perguntas, dúvidas temporárias e certezas provisórias e pesquisa. $\mathrm{Na}$ escolha das inúmeras ferramentas disponíveis para edição, pelo grupo de alunos envolvidos, pode-se partir da busca de respostas satisfatórias ao desafio proposto (pelos próprios alunos ou em parceria com o professor) através de uma postura colaborativa. As ações que são realizadas, para dar resposta ao desafio, podem envolver pesquisas em tutoriais na internet; instrução; observações e trocas de informação entre os grupos, entre outros recursos. Os alunos depuram as informações necessárias para construir o conhecimento sobre como usar a ferramenta e apresentar seu trabalho, construindo suas sínteses e validando, analisando suas dúvidas e certezas iniciais (Carvalho, Nevado e Menezes, 2005).

\section{Descrição da Experiência e Estratégias Metodológicas}

O Pbworks da escola, http:// escolanusai.pbworks.com, foi criado em 2007, concebido como uma extensão do espaço de trabalho para a maioria das atividades realizadas na SAI, com a finalidade de proporcionar o uso das novas tecnologias, mesclando conhecimentos teóricos com práticos para constituir aprendizagens colaborativas, a partir dos conteúdos propostos pelos professores ou pelos próprios alunos.

O espaço é composto pela FrontPage que dá acesso à biblioteca virtual, história da escola, chat, mural de recados, blog de Língua Portuguesa, regras de uso, vídeo das turmas, fotos de diferentes atividades e, pelo Sidebar, um menu lateral que dá acesso a links internos, outros espaços e sites externos ao PBworks, como páginas das disciplinas, portfólios, projetos e atividades desenvolvidas com e pelos alunos no período letivo.

Entre as construções desenvolvidas e apresentadas encontram-se os portfólios individuais e das turmas, projetos de estudo, projetos de trabalho e projetos de aprendizagem, desenvolvidos a partir de 2006; oficinas realizadas com professores, alunos e comunidade escolar; sites de jogos pedagógicos selecionados a partir das propostas curriculares desenvolvidas para o Ensino Fundamental, programas pedagógicos para downloads dos Sistemas Operacionais Windows e Linux.

Os Portfólios são páginas que abrigam textos e imagens, com reflexões sobre as aprendizagens, tecidos pelos próprios alunos, em textos individuais ou coletivos, esses textos são retocados, às vezes apagados, refeitos, num constante movimento de açãoreflexão que traduz o próprio ato de aprender. Ao fazê-lo, os alunos se expressam em diferentes linguagens, evidenciando o que construíram como aprendizagem sobre os conteúdos trabalhados. O Portfólio representa uma proposta atual de educação que propicia uma avaliação da aprendizagem em consonância com as finalidades educativas tornando-se uma ferramenta de apoio à avaliação para o professor, não considerando-a 
como mensuração de conteúdos para a aprovação, mas sim um indicativo do que já foi construído pelo aluno e do que ainda não foi.

Os Projetos de Estudo (PE), conduzem os alunos a se empenharem em aprender especificamente sobre um conteúdo, um lugar, uma doença, etc., que o professor tenha dado em aula ou indicado que aprofundassem individualmente, para isso, podem trabalhar sozinhos ou formar grupos. Nesse caso, os instrumentos para pesquisa, armazenagem das informações e apresentação são sugeridos na SAI, o professor esclarece dúvidas e discute com os alunos a respeito da estratégia que adotarão para a pesquisa, cronograma de trabalho, objetivos a atingir e interfere, o mínimo possível, no seu desenvolvimento, a não ser quanto ao uso adequado da língua e outras situações em que será solicitado.

Nos Projetos de Trabalho (PT), os alunos criam primeiro um objeto de aprendizagem; como a criação das páginas que irão usar dentro do PBworks. Esse objeto, embora seja único, por ser construído por cada aluno para uso pessoal, torna-se um projeto de turma, pois nenhum aluno quer ficar à parte dessas construções. $\mathrm{O}$ processo não anda parelho, pois cada aluno tem seu ritmo influenciado por suas facilidades e dificuldades. Para apoiar essas construções várias estratégias são adotadas, como tutoriais, formação de monitoria, audiovisuais, etc., a fim de auxiliar no processo. No PT, o aluno aprende e desenvolve as habilidades necessárias para sua construção no desenvolvimento do próprio trabalho.

Os Projetos de Aprendizagem (PA) possuem passos bem delimitados, como pergunta norteadora, quadro de dúvidas e certezas, pesquisa em materiais diversos, como livros, internet e entrevistas, a fim de montar um texto final, que contemple o todo das aprendizagens construídas em cada grupo. Contudo, pode-se desenvolver um PA com um único assunto para a turma toda, ou assuntos diferentes por grupos, sempre escolhidos pelos alunos. A realidade de cada turma indicará para o professor a necessidade de adaptações na formatação original do PA, lançando mão de muitas perguntas, ou de uma pesquisa prévia à formulação das perguntas. Conforme a realidade, adotam-se estratégias distintas para compor os desafios. As aprendizagens tornam-se significativas porque surgem da curiosidade natural, da necessidade ou de uma proposta sedutora e, são orientadas pelo professor, para a construção de conhecimentos necessários à vida em sociedade, como a língua, as ciências naturais e sociais, o pensamento matemático, etc.

As Oficinas Pedagógicas baseiam-se na construção de espaços de aprendizagem, onde o sujeito possa atuar de maneira global, vivenciando brincadeiras, e explorando jogos, brinquedos ou ferramentas no seu sentido mais amplo. A oficina é a oferta de um tempo e espaço determinado para o sujeito brincar, experimentar, testar hipóteses, construindo seu conhecimento. Nas oficinas são oferecidas atividades livres que trabalham com a criatividade do sujeito e também dirigidas, pois é importante saber ouvir e entender o que se pede, tanto como trabalhar com liberdade. Ao final da oficina, todos os participantes precisam apresentar um resultado. As atividades executadas em todas as oficinas têm como objetivo estimular determinadas inteligências. As oficinas são a oferta de tempo e espaço para a execução de diversas atividades. 
A informática vem acompanhada de uma nova dinâmica, em parceria com a integração curricular, pois se caracteriza pelo acesso e troca de pensamento científico, desenvolvido na autonomia, no trabalho em grupo e no senso ético. Sendo assim, a necessidade de verificar com professores e alunos, quais conteúdos poderão ser desenvolvidos na SAI, através de jogos, para sua sistematização. A proposta de trabalhar com jogos pedagógicos está em concordância com os Referenciais Curriculares Nacionais, com os Referenciais Curriculares Lições do Rio Grande e o Projeto Político Pedagógico da Escola, que apontam para a necessidade de trabalhar as TICs interdisciplinarmente e de forma lúdica no Ensino Fundamental. Através dos jogos os alunos utilizam o computador como meio interdisciplinar. $\mathrm{O}$ computador introduz recursos que desestabilizam as práticas convencionais de educação, estimulando a produção de novos conhecimentos através da interação dos alunos com a máquina. Ao jogar, o aluno desenvolve a investigação, é desafiado a explorar conceitos e ideias, por vezes pré-estabelecidas. No jogo, o aluno relaciona ideias, formula hipóteses, faz explorações e conclui como no processo científico, além de desenvolver as habilidades necessárias, de forma lúdica, para o contínuo uso do computador.

\section{Considerações Finais}

A aprendizagem em Informática Educativa se reveste da intencionalidade de provocar na criança o processo de aquisição e interpretação da língua escrita e da realidade e usá-lo realimentando o processo de investigação e experimentação que o uso do computador exige (Papert, 1994).

Para desenvolver efetivamente uma educação cidadã e de qualidade, não basta instalar laboratórios de informática nas escolas e utilizar o computador como substitutivo das ferramentas tradicionais usadas pelo professor em sala de aula. É preciso desenvolver um espaço e um tempo para as novas propostas em que o Laboratório de Informática seja um espaço interdisciplinar, seu professor responsável atue como um servidor de apoio, administrando o hardware e disponibilizando multimídias e recursos hipermidiáticos para um trabalho em parceria com seus pares nos diferentes campos do saber. Esta ideia também é corroborada por Nardin, Fruet e Bastos (2009) que referem que a inclusão de um ambiente à distância na educação não implica, necessariamente, novas práticas escolares. Desta maneira, é essencial que os professores, ao mediarem este processo, procurem se atualizar visando explorar ao máximo o potencial tecnológico e educacional. Nesse sentido, necessitam de habilidades distintas para apresentar as informações, planejar, desenvolver e avaliar estratégias de ensinoaprendizagem, além de saber selecionar quais tecnologias são mais adequadas para um determinado contexto escolar e sempre problematizá-las.

O mundo evolui em uma velocidade vertiginosa, razão de a tecnologia ser cada vez mais presente e necessária na vida das pessoas. Uma educação de qualidade visa à construção de competências e habilidades, para que o sujeito possa atuar de forma cidadã, contribuindo para a qualidade de vida, pessoal e da comunidade a qual pertence. O PBworks da Escola pretende desafiar os alunos para que sejam capazes de resolver problemas com base em conhecimentos pré-existentes e, com isso, desenvolvam a flexibilidade cognitiva para resolvê-los. 
O planejamento de atividades online repousa nas teorias construtivistas e do Acoplamento Estrutural (Maturana, 2001), que postulam a importância de se aprender na convivência e troca com o outro e com o meio, para nossa transformação e do próprio meio. Teorias que apontam a nossa influência sobre os objetos, e dos objetos sobre nós (no caso a internet e a interação com os pares), como indispensável para o crescimento, a compreensão e o entendimento do mundo, elementos importantes para aprendizagens e para o desenvolvimento da alteridade.

Concordamos com Moran (2003) que, atualmente, ensinar e aprender não se limitam ao trabalho dentro da sala de aula. Esse processo necessita de uma transformação do que fazemos dentro e fora dela, no presencial e no virtual. Necessitam de um planejamento das ações de pesquisa e de comunicação que possibilitem continuar aprendendo em ambientes virtuais, acessando páginas na Internet, pesquisando textos, recebendo e enviando novas mensagens, problematizando questões em fóruns ou em salas de aula virtuais, divulgando pesquisas e projetos.

Esse trabalho iniciou em 2007 e continua em andamento (2012), sendo uma construção contínua entre professores e alunos, ou seja, é uma proposta de construção e reconstrução diárias, exigindo colaboração e cooperação. Atualmente está se transformando numa rede em que professores e alunos conectam a partir de suas casas ou outros locais. Os "comentários" são muito utilizados por todos, já a parte de edição é usada pelos alunos, quando engajados em algum projeto na SAI.

\section{Referências:}

Bittencourt, Juliano; Kist, Sílvia; Tatizana, Décio; Schafer, Patrícia; Fagundes, Léa (2011) Ambientes virtuais de aprendizagem na modalidade 1:1: um estudo de caso sobre o AMADIS na Fase I do Programa UCA. . RENOTE - Revista Novas Tecnologias na Educação, Porto Alegre, v. 9, n. 2.

Carvalho, M.J. S.; Menezes, C.S. \& Nevado, R.A. (2005) Arquiteturas Pedagógicas para Educação a Distância: concepções e suporte telemático. In: Simpósio Brasileiro de Informática na Educação, Juiz de Fora - MG. http://arquiteturaspedagogicas.pbworks.com/f/Arquiteturas_Pedagogicas.pdf Acessado em:_17/09/2010

Fagundes, L. da C. \& Maçada, D. L. \& Sato, L (2000) S. Aprendizes do Futuro: as inovações começaram!. Brasília: Estação Palavra. http://www.oei.es/tic/me003153.pdf Acessado em 12/11/2010

Gomes, Mayra; Soares, Rosana; Leite, Andrea. Wiki: uma experiência pedagógica. Revista Online de Comunicação Linguagem e Mídias (2009). Disponível em: $<$ www.rumores.usp.br/gomes.pdf $>$ Acesso em: 28 maio de 2009.

Haetinger, Daniela; Rela, Eliana; Gelatti, Lilian; Konrath, Mary Lúcia; Kist, Tânia; Carvalho, Marie Jane; Nevado, Rosane (2006) Formação de Professores e Práticas Pedagógicas no Contexto Escolar das Séries Iniciais. RENOTE - Revista Novas Tecnologias na Educação, Porto Alegre, v. 4, n. 2. 
Mattos, Eduardo Britto; Júnior, José Carlos; Mattos, Milena Vitello (2005) Projetos de Aprendizagem e o Uso de TIC's - Tecnologias de Informação e Comunicação: Novos Possíveis na Escola. RENOTE - Revista Novas Tecnologias na Educação, Porto Alegre, v. 3, n. 2.

Maturana, Humberto R (2001). Cognição, ciência e vida cotidiana. Organização e tradução Cristina Magro, Victor Paredes. - Belo Horizonte: Ed. UFMG, 203p. (Humanitas). Em: http://livrosdamara.pbworks.com/f/Humberto Maturana Cognição, Ciência e Vida Cotidiana.pdf

Moran, J. M. Educação inovadora presencial e a distância (2003) Disponível em: $<$ http://www.eca.usp.br/prof/moran/inov_1.htm> Acesso em: 05 de set. 2008.

Nardin, A.C.; Fruet, F.S.O. ; Bastos (2009) Potencialidades Tecnológicas e Educacionais em Ambiente Virtual de Ensino-Aprendizagem. RENOTE, Revista Novas Tecnologia na Educação, V. 7 n. 3.

Papert, Seymour (1994) A Máquina das Crianças: repensando a escola na era da informática. Porto Alegre: Artes Médicas.

Piaget, Jean. Sobre a pedagogia (1998) São Paulo: Casa do Psicólogo.

Real, Luciane Magalhães Corte (2007) Aprendizagem amorosa na interface Escola, Projetos de Aprendizagem e Tecnologias Digitais. Tese de Doutorado, PGIE/UFRGS.

Real, L. M. C. ; Axt, Margarete ; Maraschin, Cleci (2007) Projetos de Aprendizagem e Tecnologias Digitais: uma experiência promovendo transformações na convivência na escola. RENOTE. Revista Novas Tecnologias na Educação, v. 5, p. 9c.

Real e Corbellini (2011). Proposta de uso de Wiki como Arquitetura Pedagógica: cooperação. In: XXII Simpósio Brasileiro de Informática na Educação e XVII Workshop de Informática na Escola (SBIE e WIE).

Real, L. M. C. ; Picetti, J. S (2011) Aprendizagens por possibilidades de deslocamentos em um Laboratório de Informática: um estudo de caso no Ensino Fundamental. In: $22^{\circ}$ Simpósio Brasileiro de Informática na Educação, 2011, Aracaju. Anais do XXII SBIE - XVII WIE, v. Trilha. p. 1-4.

Schäfer, Lacerda e Fagundes, (2009) Escrita colaborativa na cultura digital: ferramentas e possibilidades de construção do conhecimento em rede RENOTE. Revista Novas Tecnologias na Educação, v. 7, n. 1. 